\title{
EFFECT AND OUTCOME OF HARMFUL TRADITIONAL PRACTICE OF ORAL ADMINISTRATION OF MERCURY IN NEWBORN AND INFANTS
}

\author{
Chidambaranathan Sivaprakasam¹, Ragavendran Jagannathan², Logesvar Palanisamy33, Ramesh Samikannu${ }^{4}$
}

${ }^{1}$ Reader, Department of Paediatrics, Rajah Muthiah Medical College and Hospital, Chidambaram, Tamilnadu, India.

2Postgraduate Student, Department of Paediatrics, Rajah Muthiah Medical College and Hospital, Chidambaram, Tamilnadu, India.

${ }_{3}^{3}$ House Surgeon, Department of Paediatrics, Rajah Muthiah Medical College and Hospital, Chidambaram, Tamilnadu, India.

4 Professor and HOD, Department of Paediatrics, Rajah Muthiah Medical College and Hospital, Chidambaram, Tamilnadu, India.

\begin{tabular}{l}
\hline ABSTRACT \\
BACKGROUND \\
Oral mercury administration in newborns and infants is being followed as traditional practice in some rural areas around \\
Chidambaram, Tamilnadu. The symptomatology is similar to a systemic illness like septicaemia. Failure to recognize the \\
administration can lead to neonatal demise.
\end{tabular}

\section{MATERIALS AND METHODS}

It is a descriptive study and was conducted during March 2003 to March 2017 for a period of fourteen years. Newborns and infants admitted with the history of mercury administration or their X-ray abdomen showing mercury pellets were included while those with congenital anomalies and preterm babies were excluded. They were further investigated and treated, on the basis of the presentation.

\section{RESULTS}

Total children in the study was forty three neonates and infants, twenty five (58.13\%) were given mercury on the first day of life for acrocyanosis. Thirty eight babies (88.37\%) became symptomatic on third to fifth day of administration. The common presentations were refusal of feeds, abdominal distension and respiratory distress. All cases were treated symptomatically. Of 43 babies, 31 improved without any complications and 12 babies developed paralytic ileus. Ten babies died with progressive rise in liver enzymes and jaundice, despite the intervention.

\section{CONCLUSION}

Health education and awareness must be spread in the community regarding mercury toxicity. Long term effects of mercury should be studied further, as the mercuric salts can be retained in various organs of the body for many years.

\section{KEY WORDS}

Acrocyanosis, Mercury Pellet, Newborns and Infants, Abdominal Distension.

HOW TO CITE THIS ARTICLE: Sivaprakasam C, Jagannathan R, Palanisamy L, et al. Effect and outcome of harmful traditional practice of oral administration of mercury in newborn and infants. J. Evolution Med. Dent. Sci. 2019;8(02):114-116, DOI: $10.14260 /$ jemds/2019/25

\section{BACKGROUND}

Heavy metal toxicity accounts for a large number of diseases but is uncommon in children especially the newborns and infants. The most common heavy metal toxicity in children aged 1 to 5 years is recurrent lead poisoning accounting for $1.4 \%$ based on serum lead levels.[1] Oral mercury administration in newborn and infants is a traditional practice in the rural areas of Tamilnadu. [2] The symptomatology is similar to a systemic illness like septicaemia. Failure to recognize this administration due to inadequate history taking or appropriate investigation can lead to neonatal demise.[3] Metallic mercury is a shiny, silver coloured and odourless liquid.[4]

'Financial or Other Competing Interest': None.

Submission 10-08-2017, Peer Review 30-12-2018,

Acceptance 08-01-2019, Published 14-01-2019.

Corresponding Author:

Dr. Chidambaranathan Sivaprakasam,

Department of Paediatrics,

Rajah Muthiah Medical College and Hospital,

Annamalainagar,

Chidambaram-608002,

Tamilnadu, India.

E-mail: cdnathan@hotmail.com

DOI: $10.14260 /$ jemds/2019/25

\section{(c) $(1)(9)$}

\section{MATERIALS AND METHODS}

This study was conducted at the Department of Paediatrics, Rajah Muthiah Medical College \& Hospital, Chidambaram, Tamilnadu. It is a descriptive study and conducted from March 2003 to March 2017 for a period of fourteen years. Newborns and infants admitted with the history of mercury administration or their X-ray abdomen showing mercury pellets were included (Figure-1). Those with congenital anomalies and preterm were excluded from the study. Thorough history including the locality, socio economic status, type of family, reason for mercury administration, availability of mercury, ingredients given along with it, time of administration, time interval between administration and development of symptoms were obtained from the mother or a care taker. Details regarding birth, maturity, birth weight, feeding habits were also noted. The symptoms of mercury administration like poor feeding, abdominal distension, respiratory distress, convulsions were also noted in the history. Complete physical examination was performed and complications of mercury administration like abdominal distension, dyspnoea, pallor, bulging anterior fontanelle were also noted. The following investigations were done for all cases included in the study: Complete haemogram, urine analysis, stool examination, blood grouping, peripheral smear, renal \& liver function tests, septic screening and 
radiological evaluation including X-ray chest with abdomen \& USG cranium. Cerebrospinal fluid analysis was done in selected cases. Based on their clinical presentations, treatment was initiated. Most babies were treated successfully with nil per oral, nasogastric aspiration with gastric lavage, antibiotics (cefotaxime and metronidazole), diuretics, anti-convulsants (phenobarbitone and phenytoin), appropriate replacement of red blood cells and total parenteral nutrition. Chelating agents were not administered as the pellet can't be absorbed systemically.

\section{RESULTS}

Fifty-two new born babies were admitted with a history of oral mercury administration and/ or x-ray showing mercury pellets. Forty-three babies constituted the actual study population, 9 babies were excluded based on the selection criteria. Among the 2476 newborn admissions, fifty-two had oral mercury administration. The male to female ratio was 1.4:1. All the babies belong to the lower socio-economic status. Eighty seven percent of babies were from the rural population. Eight one percent of the babies were from the joint families. Ninety percent of the babies were given mercury as per the advice of grandmother. Thirty-seven babies had a history of mercury administration on the first day of life, while others in their third week of life. Thirty-eight (88.37\%) babies developed symptoms within 3 to 5 days after instillation of mercury (Table-1), remaining developed symptoms within 6 to 10 days after instillation. Of the fortythree babies, twelve babies (27.9\%) developed complications like paralytic ileus, recurrent apnoea, meningitis, ileus, septicaemia, refractory seizures and renal failure with survival of only two babies (Table-2).

Despite effective treatment, mortality in the complicated cases was $83.33 \%$. But in babies without complications the mortality percent was zero. Haemoglobin estimation showed anaemia in 15 (34.88\%) newborns and infants with microcytic hypochromic anaemia in 9 (20.93\%) of these babies. There was evidence of sepsis in the form of elevated CRP levels and elevated neutrophil counts with polymorphonuclear predominance in 16 babies (37.2\%). Among the complicated cases, 6 babies had E. coli in the blood culture and cerebrospinal fluid analysis confirmed meningitis in 7 babies (58.33\%). Stool examination was positive for mercury pellets in 28 babies $(65.11 \%)$. There was evidence of renal involvement in 16 babies of which 7 babies $(43.75 \%)$ developed acute renal failure. Three babies $(7 \%)$ had elevated liver enzymes on admission which returns normal after 5 days. The mean hospital stay was $13.5 \pm 2.3$ days.

\begin{tabular}{|c|c|c|}
\hline Symptoms & $\begin{array}{c}\text { Total } \\
\text { Number } \\
(\mathbf{n = 4 3 )}\end{array}$ & $\begin{array}{c}\text { Percentage } \\
\mathbf{( \% )}\end{array}$ \\
\hline Poor Feeding & 25 & 58.14 \\
\hline Abdominal Distension & 15 & 34.88 \\
\hline Breathlessness & 13 & 30.23 \\
\hline Fits & 7 & 16.28 \\
\hline Vomiting & 6 & 13.95 \\
\hline Reduced Urine Output & 6 & 13.95 \\
\hline Loose Stools & 3 & 6.98 \\
\hline Incessant Cry & 3 & 6.98 \\
\hline Table 1. Presenting Symptoms of Oral Mercury \\
\hline \multicolumn{2}{|c}{} \\
\hline \multicolumn{2}{|c|}{}
\end{tabular}

\begin{tabular}{|c|c|c|}
\hline \multicolumn{3}{|c|}{ Administration } \\
\hline Signs & Total Number (n=43) & $\mathbf{( \% )}$ \\
\hline Abdominal Distension & 18 & 41.86 \\
\hline Dyspnoea & 16 & 37.21 \\
\hline Pallor & 16 & 37.21 \\
\hline Anterior Fontanelle Bulge & 12 & 27.91 \\
\hline Abnormal Posturing & 9 & 20.93 \\
\hline Seizures & 9 & 20.93 \\
\hline Hyperthermia & 6 & 13.95 \\
\hline Shock & 4 & 9.30 \\
\hline Table 2 Signs of Oral Mercury Administration
\end{tabular}

Table 2. Signs of Oral Mercury Administration

\begin{tabular}{|c|c|c|}
\hline Treatment Outcome & Total Number $(\mathbf{n = 4 3 )}$ & $\mathbf{( \% )}$ \\
\hline Treated & 33 & 76.75 \\
\hline Expired & 10 & 23.25 \\
\hline
\end{tabular}

Table 3. Outcome of Oral Mercury Admination in Newborns and Infants
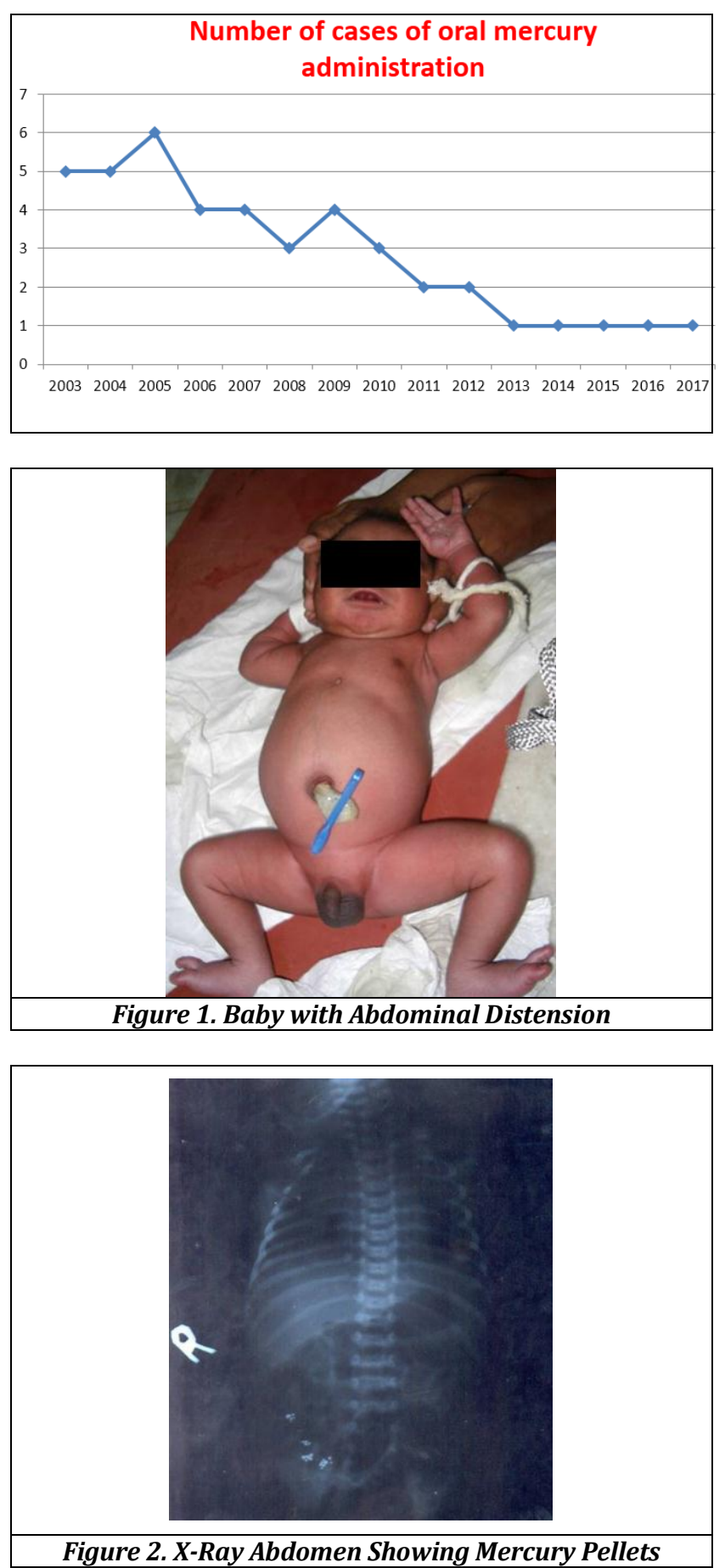

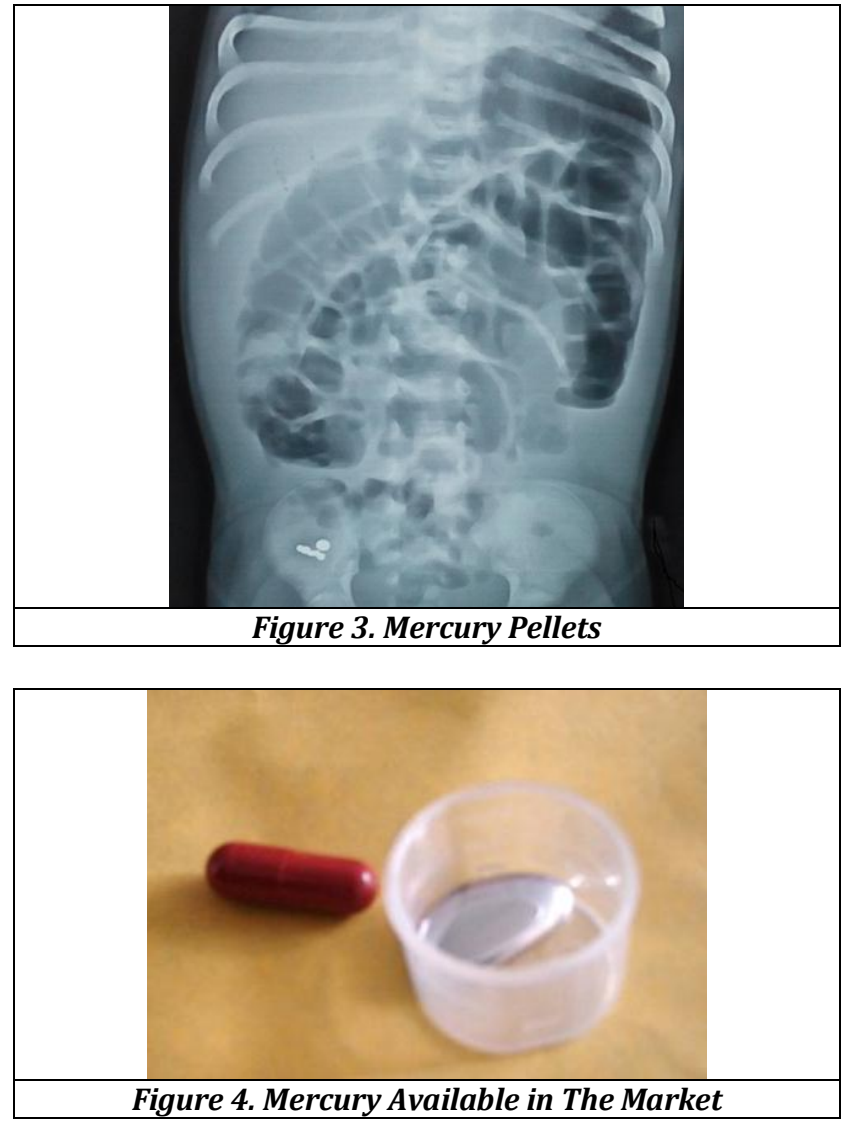

\section{DISCUSSION}

Metallic mercury is a shiny, silver coloured and odourless liquid. When administered orally it is not absorbed and excreted in stools [5]. It is given as traditional practice to newborns for checking 1) the patency of the gut and 2) for relieving acrocyanosis (Karapan). But when given as mixture with other ingredients (Like Ocimum sanctum (Tulasi), Cuminum cyminum (Cumin), Trachyspermum copticum (Carom) it gets adsorbed on the gut wall and produces the manifestations. On exposure to mercury the person develops a clinical condition called "PINK DISEASE" featured by flushing, itching, raised BP, excessive sweating and irritability. The flushing produces erythema of the extremities, which serves its purpose to combat acrocyanosis [6]. Other symptoms include cough, respiratory distress, vomiting, diarrhoea, severe renal damage or with CNS symptoms like spasticity, convulsions, and abnormal reflexes $[6,7]$.

Oral administration of mercury is a harmful traditional practice, in which healthy term newborn and infants are the common victims [7]. It is a peculiar problem prevalent in Cuddalore district. It is widely used in jewellery shops, which is a thriving business in Chidambaram. The use of chelating agents in newborn and infants is controversial because they are not excreted by the immature kidneys and liver [8]. As these organs are relatively immature in newborn and infants and severely affected newborn and infants had some degree of renal impairment, so the use of chelating agents was deferred [9]. Reports of elemental mercury vapor exposure in children through accidents and occupational practices, and the more recent observations of the increasing use of elemental $\mathrm{Hg}$ for magico-religious purposes in urban communities are increasing reported $[9,10]$. Elemental and inorganic mercury are used in some traditional therapies and religious practices, for example, Santeria or Espritismo or Ayurvedic medicine. For ritual reasons, mercury might be burned in a candle, spread in the room, carried as a talisman, or used in another manner [10].

\section{CONCLUSION}

Health education and awareness must be spread in the community regarding mercury toxicity. Long term effects of mercury should be studied further, as the mercuric salts can be retained in various organs of the body for many years.

\section{REFERENCES}

[1] Gao Z, Ying X, Yan J, et al. Acute mercury vapor poisoning in a 3-month-old infant: a case report. Clin Chim Acta 2017;465:119-22.

[2] Rizvi SJ, Zahir F, Jairajpuri DS. Mercury: the lurking danger. Anil Aggrawal's Internet Journal of Forensic Medicine and Toxicology 2005;6(1).

[3] Chang JY, Park JS, Shin S, et al. Mercury exposure in healthy Korean weaning-age infants: association with growth, feeding and fish intake. Int J Environ Res Public Health 2015;12(11):14669-89.

[4] Jering $K$, Aschner $M$, Beller $A$, et al. Parenteral nutrition as an unexpected and preventable source of mercury exposure in preterm infants. J Pediatr 2015;166(6):1533-5.

[5] Rice KM, Walker EM Jr, Wu M, et al. Environmental mercury and its toxic effects. J Prev Med Public Health 2014;47(2):74-83.

[6] Ng S, Lin CC, Hwang YH, et al. Mercury, APOE and children's neurodevelopment. Neurotoxicology 2013;37:85-92.

[7] Fahrion JK, Komuro Y, Li Y, et al. Rescue of neuronal migration deficits in a mouse model of fetal Minamata disease by increasing neuronal $\mathrm{Ca} 2+$ spike frequency. Proc Natl Acad Sci U S A 2012;109(13):5057-62.

[8] Weisser K, Bauer K, Volkers P, et al. Thiomersal and immunisations.

Gesundheitsforschung 2004;47(12):1165-74.

[9] Dargan PI, Gawarammana IB, Archer JRH, et al. Heavy metal poisoning from Ayurvedic traditional medicines: an emerging problem? Int J Environ Health 2008;2:463-74.

[10] U.S. Environmental Protection Agency. Task force on ritualistic uses of mercury - EPA/540-R-01-005. Washington, DC: 2002. 